\title{
Strategies of Application of Digital Tools of Small Business Management During the Coronavirus Pandemic
}

\author{
Akmaeva R.I.* Maksimov I.V. Glinchevskiy E.I. \\ Astrakhan State University, Astrakhan 414056, Russian Federation \\ *Corresponding author. Email: akmaevari@yandex.ru
}

\begin{abstract}
Keywords: trends, digital tools, business models, small business

\section{INTRODUCTION}

Analyzing how digital tools might be applied at small and middle-size enterprises, which have been affected by the current pandemic most seriously, is believed to be quite urgent. The recent UN report states that the COVID-19 crisis submerges the world economy in recession with historic levels of unemployment and poverty [1]. The social and economic consequences of the coronavirus pandemic are so serious that the United Nations may be right when it appeals to build a new post-pandemic economy immediately.
\end{abstract}

This paper concerns new technological trends of digitalization processes related to small and middle-size businesses; it proves that the current crisis and its consequences will undoubtedly speed up digitalization of Russian companies. The article also gives grounds for the statement that owing to broken traditional links and operation methods, the coronavirus crisis has made all the companies change fast and develop a new strategy during the pandemic, as well as think about their post-pandemic development strategies. This paper states that business models, which are currently changing, will be undergoing substantial changes during the post-crisis period owing to integration of cutting-edge digital technologies. The article points out that the lessons that small business managers will learn from the coronavirus consequences shall determine the fate of their companies and the entire national economy in both the short-term and the long-term run. The paper suggests that the task of total digitalization of small businesses should be resolved by applying joint efficient management solutions and a special state information system to search and select efficient and relatively inexpensive digital projects to be implemented in small businesses.

\section{RESEARCH GOAL AND METHODS}

This research aims to analyze new technological trends of digitalization processes at small and middle-size business enterprises, as well as work out their development strategies for the crisis and the post-crisis periods.

\section{RESULTS}

The impact exerted by the pandemic has affected business companies' confidence in their corporate image and reputation. The recent summer survey conducted by the Worldcom Public Relations Group in August 2020 reveals that the Business Confidence Index (BCI) has been stabilized at quite low values. The Worldcom Confidence
Index, which indicates confidence in corporate reputation, had decreased by $28 \%$ by 2018 and achieved the value -5 $\%$. One should note that issues of personnel management assume the leading positions in business involvement: staff's upskilling and reskilling $(+6 \%)$; sustaining the brand of an attractive employer (+2\%); employee engagement $(+1 \%)$; retaining talented members of staff $(+1 \%)[2]$.

Analysts of Accenture Consulting have researched which trends will influence people and businesses during the post-pandemic era. First, the pandemic has changed the role and importance of customers' digital expertise suffice it to say that e-commerce has been growing enormously all over the world. Only in the USA, according to Visa, costs for online sales have grown by 18 $\%$ [3].

Second, the ranking of TechTrends is changing. In particular, a pre-pandemic Technology Vision survey revealed that $73 \%$ of companies are planning to implement or already implementing the Artificial Intelligence (AI) in one or several business units, whereas in June 2020, the AI is already becoming a crucial field in digitalization, which is proved by numerous cases of its application at industrial and healthcare facilities and in the sphere of services. In Shenzhen, the Youlbot startup has constructed an antivirus robot within just two weeks; the robot disinfects surfaces and scans patients' and visitors' body temperature [3].

However, the most urgent TechTrend as for June 2020 is active robotization. Owing to distance work, maintaining 
the distance is becoming a norm. Robots are shifting from specialized industries to an unlimited environment; they can help people isolated from each other. Here is a number of examples: XAG, which is a Chinese agricultural technological company, has modified its XPlanet drones and R80 robots to spray disinfecting agents in areas affected by the coronavirus.

In the long-term run, the entire ecosystem of robotics will definitely be developing faster than before. Robotization will cause a rapid development and a large-scale application of the Internet of Things (IoT) and the virtual reality (VR), especially in telemedicine and education.

The pandemic has caused an increased demand in the development of high technologies. In particular, it has sped up adaptation of the DARQ technologies (distributed ledger technology, AI, extended reality, and quantum computing). Technological innovations, for which companies had to prepare for several years, are becoming available within just a few weeks in June 2020, since the conditions of the pandemic require that companies should introduce innovations and reconsider their approaches to business operation within the shortest time.

The International Data Corporation (IDC) has published its forecast, which states that expenses for corporate blockchain projects will rise by $60 \%$ in Europe in 2020, despite the coronavirus pandemic that caused serious problems in international supplies. Long and complex supply chains complicate forecasting and planning of supplies; blockchain may resolve this issue, since its advantages are a transparent supply chain and easy tracking of transactions [4].

According to $\mathrm{M}$. Grigorieva, Managing Director of Accenture Technology, the current crisis and its consequences shall definitely speed up digitalization of Russian business [3]. Projects related to e-commerce and digital distribution channels are becoming urgent; there is a growing demand for transport control and planning systems, which will ultimately make it necessary to obtain and analyze the Big Data concerning clients, changing demand, price fluctuations, etc. A peculiar feature of the present-day reality is that focus is shifted to application of ready-made solutions, which can provide a real result within a short time. General Motors and Tesla, as well as a number of Russian companies, produce artificial pulmonary ventilation equipment. Russian companies apply their perfume and cosmetic production lines to manufacture disinfecting agents for hands, which are supplied to hospitals without charging any money. DyunaAST, which is located in Astrakhan, has promptly redirected its production to manufacture medical protection products.

Over the six months of the pandemic, a new field of applying digital tools has even emerged - CovidTech. This field includes systems to track and control people's movements to prevent the incidence rate from increasing; cloud video conferences and online education for which demand is rising; information services to provide prompt help in emergencies; development of technological cooperation between businesses, research institutes, and legal authorities.
Small and middle-size companies, which have suffered from the pandemic most seriously, play a special role to develop a new field of applying digital tools in present-day Russia.

Thus, all these changes, which are due to the coronavirus pandemic, confirm that the United Nations may be right when appealing to build a new economy immediately once the pandemic has been over [1]

On the other hand, K. Terzioglu, Co-CEO of the Veon Holdings B.V., said in the interview which he gave to the Vedomosti that the COVID-19 pandemic contributed to the tenfold growth in the world economy digitalization [5]. $\mathrm{He}$ believes that the Internet and networks are the main factor to provide existence of communities, countries, people, and businesses.

Experts forecast that even despite development of vaccines against the coronavirus, the main support during the postpandemic period will be provided for such technological spheres as the AI, 5G, innovative medical technologies, and distance education tools.

\section{DISCUSSION}

The crisis has broken traditional links and operation methods, which has made all the companies change rapidly and develop a new strategy over the pandemic period, as well as think about the post-coronavirus development strategies.

The entire world is facing an ideal storm: from plummeting oil prices and slumped stock markets to broken supply chains and liquidated businesses, which has resulted in insufficient liquidity and a considerable decrease in revenues all over the world. COVID-19 has become the main problem of the global economy, which makes businesspeople and investors change their plans, think about their businesses' survival and their postpandemic development strategies.

Therefore, management of companies has to consider two main points: first, what to do with their businesses now to ensure their survival (since business strategies require urgent changing and the entire situation changes every single day); second, management has to consider their future strategies to change their business models radically in order to make them correspond to the current reality. The differences between the notions "business model" and "business strategy" in strategic management are ambiguous. A business model is a business concept based on these or those sources of revenues; it does not consider competition; on the other hand, a business strategy ought to take competition into account. Companies may apply similar business models; however, their success or failure is determined by their business strategies that indicate which company is able to create a sustainable comparative advantage [6].

While developing both business models and business strategies, company management (especially small businesses) ought to develop their own program of strategic support of digital technologies. One should note that business models, owing to integration of cutting-edge 
technologies in all the business activities, will continue changing rapidly during the post-crisis period, when the degree of priority of many spheres does not correspond to people's demands any more, since the post-pandemic life has undergone substantial changes [7].

The processes of digital transformation require radical reconsideration of business models and diversification of activities; as a result, boundaries between different fields are erased.

That is why a crucial issue emerges: what should a business manager do to save their company now and preserve it in the future; where and how should they search for new points of growth?

The first and foremost task is to ensure staff's safety; as gained experience shows, management has been tackling this task by arranging their staff's distance work, by monitoring and sharing urgent medical information, by complying with new sanitary and hygienic requirements to treat workstations, etc. Besides, as it is well known, the strategy development horizon is decreasing, so a company should develop its plans for shorter terms -3 to 6 months - and correct those plans depending on the market situation.

A business manager should monitor the macroeconomic situation in their country; it is essential to forecast several macroeconomic scenarios (basic, negative, and positive). One should reconsider planned investments by suspending some projects and redirecting deficient resources to more viable areas, as well as by enforcing online resources. It is necessary to monitor the level of liquidity and anticipate probable cash gaps, trying to get their financial commitments postponed and (at the same time) cooperating with debtors actively.

To prevent revenues from dropping (since they always drop faster than expenses), one should focus on the income sources that correlate with the current reality most adequately; one should reconsider their range of goods and services, as well as relations with clients. As gained experience proves, one should not reject the traditional services, to which people are accustomed; one should transform those traditional services considering with clients' new needs.

Owing to irregular supplies, one should reconsider the range of suppliers to ensure continuous and stable supply, taking into account suppliers' reliability, their prices, and the quality of their supplies; one should also assess their own activities critically and eliminate unnecessary business processes.

During the current crisis, many companies commence to reduce their expenses severely: they reduce bonuses and rewards or even reject them; they stop employing new members of staff; they make their personnel take an unpaid leave; they cancel their marketing events and even dismiss their employees.

The lessons of the coronavirus crisis that business managers will have to learn now will determine the fate of businesses and the entire national economy over the next years and decades. Managers have to decide what exactly they will do during the business recovery period, what business strategy they will apply to overtake their competitors, how they will transform their business models in the post-coronavirus world to make them sustainable and highly adaptive. No doubt, the business model of a particular company will determine the speed and efficiency of its post-crisis recovery.

While selecting and assessing their product ranges, management has to consider the lessons of the crisis carefully: what could undergo radical changes in the foreseeable future from the viewpoint of, first, demand for the products that their companies manufacture, second, opportunities of mergers and acquisitions (acquiring other companies or merging with them to operate in the market niches where demand is expected), third, changes in consumers' preferences towards cheaper products owing to people's lower incomes, and fourth, rapid business digitalization trends, since demand for online services (education, purchases, entertainments) has soared and consumers can appreciate a real possibility to combine different channels to purchase products [8].

It is application of digital technologies that provides small businesses with real opportunities during the post-crisis period; those opportunities relate to switching to new business models of the digital era, which requires changes in not only software, but also correlations with suppliers, clients, competitors, and contractors. Consequently, new strategies of post-coronavirus development require changes that are more frequent; their contents ought to allow application of digital tools, especially in the field of the IoT and augmented reality (AR), which adds digital data and images to the physical world. These tools have almost become the mainstream, since they can be applied efficiently in all the spheres of economy, improving not only production processes, but also processes of education, decision-making, and interaction [9, p. 30].

It is also essential for small businesses to apply the Big Data technology, since it provides them with a new source of growth, as well as with favorable opportunities thanks to an in-depth segmentation of the client base and application of complex analytics based on mathematical models. However, large-scale implementation of IoT and AR tools seems to be more viable for small businesses' digitalization. To obtain a general concept of how these promising digital technologies might be applied, let us consider areas and conditions of their application in more details.

The IoT provides many opportunities to collect, store, process, and analyze data, as well as maintain a remote control of devices and "intelligent" systems. In particular, the GE Company controls equipment at industrial facilities in the real-time mode as follows: applying information obtained with embedded software, it reports its clients that it is necessary to repair that equipment and corrects the maintenance schedule. GE began to supply that software directly to its customers, avoiding system integrators who did that stage by stage. As for the AR tools, they will become a bridge between the digital and the physical worlds; they transform data arrays and analytics into images or animation, putting them over the real world [9, p. 33-36). 
Small businesses have to consider the role of AR in the development of their strategies and reconsideration of old business models. To meet this goal, one should assess opportunities of AR application in their field of activities and determine the degree of their priority in accordance with the adopted strategy. Selecting digital solutions in the field of AR, one should identify the strategic direction in this field in advance - whether the company will develop AR itself or it will only use outsourcing or a partnership for that. AR tools will provide small businesses with a much wider range of opportunities; they make it possible to change and enhance staff training and execute the most complicated operations with the distance help of expensive experts.

As organizational structures are becoming flatter, there is a growing need for a large-scale practical application of such organizational forms of planning activities as holacracy and Agile. They are applied to build selfmanaging teams whose members participate in management decision-making actively, change their roles, become more responsible, and trust each other more.

Therefore, not only a radical change of business models and a reduction of the strategy development horizon must take place; new organizational forms of strategic planning and realization must be implemented actively. According to the Deloitte 2017 survey, $79 \%$ of global leaders have named Agile as a top-priority method of management [10]. In our opinion, it is flexible methods that help adapt to the post-crisis conditions faster and supply innovations of both types: not only new products and services, but also innovative working processes, since adaptive teams are oriented mainly towards innovations; those are selfmanaging teams which interact with their customers actively and react to their changing requirements promptly. Agile is based on SCRUM (this term derives from rugby), which is a format of work in the Agile concept and which suggests dividing the entire project into small (from a week to a month) cycles (sprints); at the end of each sprint, ready results are presented to the customer. It is essential that each sprint resulted in a ready solution, process, or product. Thus, the Agile technology based on short sprints suggests obtainment of real results that can be applied in practice at once, as well as regular feedback from the customer. A cross-functional self-organizing team works as a single entity striving to achieve the set goal.

Our active participation in various online seminars, webinars, and forums over the isolation period makes it possible for us to conclude that particular elements and attributes of the Agile technology (15-minute standups, dashboards, customers' participation in receiving prototypes of products, etc.) are already applied by numerous Russian organizations in their everyday activities widely and efficiently. Let us hope that this technology of flexible management will be of great value for not only large, but also small companies in implementing digital tools.

Management of small and middle-size companies should learn another important lesson: the Agile method is the base to implement modern approaches to personnel management, including digital technologies, since it enhances business processes and helps build a team comprising active, productive, and creative members.

\section{CONCLUSION}

Thus, only efficient activities of company management can help small businesses cope with switching to digital business models; those activities should aim to search and select top-priority digital projects to be implemented by a small business. It will provide new opportunities for both company management and its partners, should they apply joint efforts, as ecosystems are developing rapidly.

Digital transformation can give Russian companies a new chance to liquidate technological backwardness of their country, which took place during the post-Soviet era. That is why digitalization of economy becomes of primary importance for Russian large and small businesses; it requires a far more active application of new digital tools that are relevant to the present-day reality: cloud calculations, 3D print, IoT tools, VR and AR, Big Data, blockchain, high-performance platforms to store and process data (such as HANA), etc.

A number of large companies that have the necessary funds are already implementing expensive digital technologies such as SAP/4 HANA (Severstal, the Alcohol Siberian Group); nevertheless, other large companies maintain the wait-and-see position, thus losing their competitiveness. As for small companies, their assets are so minute that they do not even dream about digital innovations, except for startups, which have already selected their niche in the field of digital technologies.

As there is a shift towards the world economy, company management has to make decisions to select the right development strategy and these or those digital innovations, so their knowledge of those innovations ought to be quite profound. That is why this work should be started by learning about digital technologies that Russian companies have already implemented successfully, and benchmark them actively. Therefore, the most crucial task for managers is to search and select particular top-priority digital projects to implement at their companies.

To meet the set goal, one should identify and clarify a list of the appropriate key steps and stages. At the initial stage, one should collect all the digital initiatives in each business or each functional unit and start their joint complex development. Managers should start this work to search and select top-priority digital projects by learning (mainly in the Internet) about digital technologies that have already been implemented at Russian companies successfully, so as to start their active benchmarking. Yet, to ensure that a well-structured approach is applied to management of digital initiatives, it is necessary to select and adopt the approach that suits this company most at the current stage of its development. There are three main types of approaches: strategic, reverse, and free. The strategic approach implies the top-down direction, which depends on a company's goals and performance indicators. In contrast, the reverse approach implies bottom-up 
initiatives: digital initiatives are considered at the level of the very processes and aggregated as a single project. The free approach means that digital initiatives are considered at the level of the very processes by applying individual performance indicators [11].

The main source of such information is the Internet, as well as webinars and seminars delivered by special professional organizations, such as the Internet of Things Association established at the initiative of the Internet Initiatives Development Fund and the Bauman Moscow State Technical University, as well as other similar organizations and institutions established by the National Research University Higher School of Economics, Peter the Great St. Petersburg Polytechnic University, etc. Practicing managers do not have a complete list of such professional organizations; if they had it, it would save time to search for the relevant information concerning digital tools that they might implement. In our view, there are two possible ways to resolve this problem: first, the government could make a decision to establish selfregulating organizations in the field of digital transformation, which would have all the necessary information to share with practicing managers; second, the appropriate units and sections of related ministries and agencies (similar to Scientific \& Technical Information Bureaus (STIB) in the Soviet era) could monitor and collect information about successful cases of implementation of digital innovations at enterprises operating in the corresponding fields of economy. As it is well-known, Soviet-era enterprises would obtain STIB Bulletins on a regular basis, thanks to what they could learn about various innovations in their industries.

Therefore, besides independent search for information in the Internet to select efficient and inexpensive innovations for small businesses, the second stage should imply assistance provided by state authorities.

Since the most important task for management of small businesses in the post-pandemic period is to search and select particular digital tools to implement (even if a small business has insufficient assets to finance such activities), one could suggest resolving this issue by maintaining efficient cooperation between management of small businesses and a special state information system that would allow searching and selecting efficient and relatively inexpensive digital projects to be implemented at small companies, or by establishing self-regulating organizations in the sphere of digital transformation. In our opinion, one cannot resolve this issue without assistance provided by legal authorities.

In particular, Agrosignal took the initiative to act as an assistant for agricultural enterprises; it offers them relatively inexpensive digital solutions at their request. Those solutions may have been developed by Agrosignal itself, or they are currently applied in Russia successfully by other companies.

The state represented by the Ministry of Economic Development ought to assist small businesses actively by promoting topical information related to successful implementation of digital innovations in the appropriate industries or fields of knowledge. The corresponding units of related ministries and agencies should present that information on a special web site to let small businesses learn it promptly and make a decision: whom they might contact, who might offer an inexpensive digital solution, etc. The same information should be submitted to the Federal Ministry of Economic Development to centralize and generalize it. Together with investments, that information system aiming to support small businesses could contribute to a more rapid implementation of digital innovations for this or that particular industry.

\section{REFERENCES}

[1] OON prizyvaet nemedlenno stroit novuiu ekonomiku iz-za koronavirusa, https://www.tadviser.ru/index.php/ $\% \mathrm{D} 0 \% \mathrm{~A} 1 \% \mathrm{D} 1 \% 82 \% \mathrm{D} 0 \% \mathrm{~B} 0 \% \mathrm{D} 1 \% 82 \% \mathrm{D} 1 \% 8 \mathrm{C} \% \mathrm{D} 1$ \%8F:\%D0\%92\%D0\%BB\%D0\%B8\%D1\%8F\%D0\%B D\%D0\%B8\%D0\%B5_\%D0\%BA\%D0\%BE\%D1\%80\% D0\%BE\%D0\%BD\%D0\%B0\%D0\%B2\%D0\%B8\%D1 $\% 80 \% \mathrm{D} 1 \% 83 \% \mathrm{D} 1 \% 81 \% \mathrm{D} 0 \% \mathrm{~B} 0 \_\mathrm{COVID}-19$ (accessed: 16.08.2020).

[2] Vliianie koronavirusa COVID-19 na ekonomiku stran mira, https://www.tadviser.ru/index.php/

[3] Fjord Trends 2020: Accenture vyiavila sem tendentcii, kotorye izmeniat biznes, https://www.accenture.com/ru-ru/company-newsrelease-fjord-trends- 2020

[4] Raskhody na korporativnye blokchein-proekty vyrastut na $60 \%$ nesmotria na koronavirus, https://devsday.ru/news/details/136050

[5] Interview to Vedomosti Newspaper, April 13, 2020, Kaan Terzioglu manages the Veon business in Russia and CIS

[6] R. Akmaeva, O. Mineva, E. Glinchevskiy, Assessment of application of modern management technologies by Russian regional business under conditions of new industrialization development, in: Advances in Social Science, Education and Humanities Research, 2nd International Scientific Conference on New Industrialization: Global, National, Regional Dimension (SICNI 2018), vol. 240, Ekaterinburg, 2018, pp. 288-292.

[7] M. Belzer, Digitalization of industry: fashion trend or necessary condition for maintaining competitiveness? Promdevelop, 2018.

[8] D. Naberezhnev, J. Jaulin, Wartime manager, Harvard Business Review - Russia, 2020, p. 36. 
[9] M. Porter, J. Heppelmann, Why every organization needs an augmented reality strategy, Harvard Business Review - Russia, 2017.

[10] D. Rigby, J. Sutherland, A. Noble, Agile at scale, Harvard Business Review - Russia, 2018.

[11] R.I. Akmaeva, A.P. Lunev, Steps to search and select digital projects to implement, in: M.S. Atabiev (ed.), National economic systems within the context of digital economy formation: Proceedings of the International Applied Scientific Conference, Nalchik, 2019, pp. 251-257. 